\title{
Nursing student and faculty perspectives following involvement in women, children, family scholars pilot program
}

\author{
Lynn D. Mohr*1, Jennifer Rousseau ${ }^{1}$, Shannon O'Shea ${ }^{1}$, Patricia Zillweger Kuehn ${ }^{2}$ \\ ${ }^{1}$ College of Nursing, Rush University, United States \\ ${ }^{2}$ Highland Park Hospital, Northshore University Health System, United States
}

Received: September 28, 2020

DOI: $10.5430 /$ jnep.v11n4p36
Accepted: December 2, 2020

Online Published: December 17, 2020

URL: https://doi.org/10.5430/jnep.v11n4p36

\begin{abstract}
Background: Mentoring by experienced faculty can provide opportunities for nursing students to grow personally and professionally in their pursuit of establishing a clinical specialty focus. At a Midwest pre-licensure nursing (pre-licensure clinical nurse leader) program, faculty sought to assist students in pursuing knowledge and experiences within the Women, Children, and Family Nursing (WCFN) specialty.

Methods: After completing an application process, selected scholars were matched with a faculty mentor to discuss student objectives/goals, project work, and engage in post-program employment opportunities conversations. At program end, both scholar and mentor completed satisfaction surveys.

Results: Surveys revealed the WCFN scholar pilot program proved beneficial for both student scholar and faculty mentor. Small program changes would improve the scholar experiences.

Conclusions: A WCFN Scholar program provides nursing students' access to experienced faculty mentors who provide encouragement, assist with problem solving, and offer professional development advice, and networking. Faculty mentors reported personal satisfaction knowing they were supporting new nurse development in the WCFN specialty.
\end{abstract}

Key Words: Nursing student, Faculty, Pre-licensure nursing, Women, children and family nursing

\section{INTRODUCTION}

With the focus on student-centered learning, a critical component of improving academic outcomes is student-teacher relationships. Positive student-teacher relationships can be facilitated by opportunities for frequent student and faculty contact. While the advisor role is helpful, often students possess an area of clinical interest which may not be the advisor's area of expertise, thus leaving the student wanting more. Literature identifies that when students feel supported by their teachers, attrition rates decline, academic success increases, and students feel motivated. ${ }^{[1]}$ At one Midwest pre-licensure general entry masters nursing program, students desired more of a connection with and support from faculty in a particular clinical interest area. There was no program that offered the opportunity to gain mentorship from an expert clinician in the area of Women, Children, Family Nursing (WCFN).

\section{BACKGROUND}

In the 2011-2015, College of Nursing's (CON) Strategic Plan, the idea of nursing scholars was introduced in the prelicensure general entry master's nursing program to increase

*Correspondence: Lynn D. Mohr; Email: lynn_mohr@rush.edu; Address: College of Nursing, Rush University, United States. 
the awareness of nursing roles in community/public health, behavioral health and older adult health specialties within the student body. The goal was that students who expressed an interest would be mentored by an expert in the field of community/public health, behavioral health and older adult health specialties who could assist in providing a broader range of experiences in the community/public health nurse role. These opportunities would focus on disease prevention through primary health care prevention and community reinvestment programs. It would be a formal program with an application process, meetings between student and mentor, and the reporting of outcomes at the completion of the program.

It was determined that after the success of the program with the CON community public health department, that this type of program could benefit students with interests in other populations. Since no program of this type was available to students with a passion and desire to engage in opportunities to advance their WCFN health interest, it was decided to pilot the program. This paper describes the purpose, process for implementation, student scholar perspectives and faculty benefits of a WCFN Scholar pilot program where faculty were matched with pre-licensure general entry masters nursing students in a mentoring relationship.

\section{LITERATURE REVIEW}

A review of the literature published from 2004 to 2019 was conducted using key words prelicensure nursing student, undergraduate nursing student, mentoring, and nurse faculty mentor. Four key themes were uncovered in the literature including student-teacher relationships, mentoring of students, immersion of student in professional culture, and benefits to students and faculty who participate in a mentoring relationship.

\subsection{Student-Teacher relationships}

In this era of student-centered learning, one component that is critical to improved academic outcomes is student-teacher relationships. Positive student-teacher relationships foster student learning and growth. ${ }^{[1-3]}$ Further, positive studentteacher relationships can be facilitated by opportunities for frequent student and faculty contact which is considered to be one of the best practices of undergraduate education. ${ }^{[4]}$ Literature identifies that when students feel supported by their teachers, they feel more motivated, attrition rates decline, and academic success increases. ${ }^{[1,5,6]}$ Notably, Al-hussami and collegues ${ }^{[6]}$ found that the degree of improvement in GPA was positively related to the amount of time spent with faculty.

Published by Sciedu Press

\subsection{Mentoring of students}

Mentoring is one strategy that nursing faculty can use to develop stronger relationships with students. Mentoring is described in the literature as a relationship between a less experienced person and one who has more experience with the goal of supporting the professional development and socialization of the less experienced person into a profession. ${ }^{[7]}$ To support professional development, the mentor will share knowledge, experience, wisdom, and perspective within a context of mutual respect and trust. ${ }^{[2]}$ Through faculty mentoring of students, faculty begin to see students as individuals, ${ }^{[3]}$ and gain knowledge about the student experience. This helps to better meet students' needs, understand their challenges, and creates a civil, caring learning environment. ${ }^{[2,3,8]}$ At the same time, students learn more about a faculty member when given the opportunity to form a mentoring relationship outside of the classroom. They learn about their area of expertise, the path of their career, and their professional roles. This process of mutual discovery helps students to realize that faculty care about them which in turn, builds trust. ${ }^{[2,3]}$ In a review of the literature, Ingraham and collegues, ${ }^{[1]}$ found that students in a mentoring relationship feel supported and cared for throughout their studies and this resulted in improved academic outcomes measured by student success and faculty morale.

\subsection{Immersion of students in professional culture}

Along with teaching students how to provide safe, efficient care to patients, an important component of nursing school is to immerse the student in professional culture. Studentfaculty interactions, such as through mentoring, that help to build a student-teacher connection can positively influence professional socialization. ${ }^{[9]}$ Mentorship in a students preferred specialty area also facilitates student-to-nurse transition. ${ }^{[10]}$ When students have a positive mentoring relationship, it may be a powerful tool they'll turn to again to enhance career development.

\subsection{Benefits of mentoring}

Faculty can benefit from mentoring students. Faculty report a sense of increased professional success and satisfaction with their faculty role when they mentor students. ${ }^{[8]}$ Dorsey and Baker $^{[8]}$ also found that participation in mentoring programs strengthened faculty leadership skills, enhanced their selfworth, and motivated them to help other students. While the faculty-student relationship provides many opportunities for mentoring and may appear to be inherent to the role, mentoring is a learned skill. McBurney ${ }^{[11]}$ recommends that mentors first determine their own style of mentoring whether for example, it is as advisor, confidant, coach, or sponsor. The mentoring style will help determine the method of communi- 
cation and meeting schedule, which could be more informal through e-mails or texts or more formal with regularly set face-to-face encounters. Despite the style and frequency of encounters, the mentor needs to help the mentee set specific goals for the experience and using the mentor's professional connections, identify and assist with participation in experiences to meet these goals. The mentor may also need to build on skills that will enhance their effectiveness such as active listening, giving honest feedback, and inspiring the mentee.

\section{Program}

\subsection{Purpose of the program}

The purpose of the WCFN Scholar Program was to provide faculty mentorship to pre-licensure generalist entry masters nursing students with a passion and desire to pursue WCFN as a specialty after program graduation. The goals of the program were to 1) provide opportunities for growth for students interested in the specialty of women and children, 2) provide assistance in navigating academic/professional resources, 3) expand the students college, university, and organizational networks, 4) role model professional etiquette, 5) begin a foundation for scholarship, (eg., poster, presentation, manuscript) and 6) assist in career planning, (eg. activities associated with gaining first WCFN nursing position and educational options post-graduation) with the intent of reducing "floundering" post graduation.

\subsection{Program process}

Our program was built to include the five major components of formal mentoring practice in nursing education as described by Dorsey and Baker: ${ }^{[8]}$ set out to accomplish specific goals, has a coordinator to oversee it, has expectations regarding the process, and has evaluation criteria. The fifth criterion, selecting mentors, was based upon faculty mentor expertise match with student clinical interest.

The WCFN Scholar pilot program began with the development of an application process and program guidelines and goals/expectations. The WCFN pilot program was open to all interested students in good academic standing who were prepared to work towards "rising above"; self-directed, motivated, flexible and held a passion for women's and children's nursing. An announcement was sent via student emails to those students completing their 4th of six terms in the program. This timeframe was selected because students would have completed some adult experiences and their women's health clinical. Thus the opportunity to develop a potential area of interest would be highest. The application process consisted of submitting a resume and cover letter addressing 1) the population of interest in women, children family nurs- ing and why this population, 2) past history of involvement in women, children family activities and 3) post-graduation plans for seeking a women, children, family career after completion of the program.

Completed applications were reviewed and in-person interviews were scheduled with the WCFN faculty responsible for oversight of the program. Interviews with two WCFN faculty (the faculty responsible for oversight and another faculty who agreed to serve as a faculty mentor) were held over a two week period with initially five student applicants. Upon completion of student interviews, the two interviewing faculty met to discuss the interviews and make scholar selections. Since both of the interviewing faculty were serving in the role of faculty mentor, student scholars were selected based upon written submission, interview and faculty mentor expertise match with student interest. Notifications of WCFN scholar selection were sent via email letters outlining their selection and their faculty matched mentor, the length of the program and expectations regarding maintaining ethical conduct as outlined in the College of Nursing Student guidebook and agreed upon meeting times which would be negotiated between mentor-mentee. For the pilot program, the mentor-mentee relationship continued formally until the student graduated. For those applicants not selected, notification letters included information about working with their advisor to gain further WCFN opportunities/activities. It should be noted that the program was limited by the number of student applications and available faculty mentors and finances should the mentor-mentee pair opt to attend outside professional offerings. At the beginning of the program, a flyer was created announcing the selected scholars with a picture and brief biography. These were distributed to the WCFN faculty department via email since some faculty work remotely and they may be contacted to provide consultation to the student/faculty pair. Having a picture and biography enhanced the building of community and engagement among students and faculty. The two faculty mentors selected and reviewed articles on the foundational concepts of mentoring which assisted in guiding the mentoring experience.

The mentoring relationship began for both faculty and student scholars over an informal lunch as a way to get to know one another. Following this initial session, each student faculty mentor pair met to determine individual goals and establish expectations. Regular meetings ensued to demonstrate progress toward individual goals. Since each student's individual goals varied, anticipated outcome goals would be varied. Outcomes could include narrowing area of professional clinical focus, expanding professional education opportunities, participating in research, resume building or, submitting a competitive abstract for presentation or publication regard- 
ing their capstone project. Each student was asked to keep a journal noting activities/experiences, thoughts/feelings about those experiences, about the student/faculty mentoring experience and any other thoughts/feelings experienced throughout the program.

Upon completion of the program, the foursome again met over lunch to discuss the experience and gather recommendations for changes. Just after graduation, the two WCFN scholars were sent a five-question survey inquiring about their perspectives regarding the program. The faculty mentors shared their perceptions regarding why they were interested in being part of the program and entering a mentoring relationship.

\section{RESUlts}

Two student WCFN scholars were selected and paired with a mentor with clinical expertise in the area of student interest. Both participants were provided verbal informed consent prior to sharing of their perspectives about participation in an end of program survey. The first question the WCFN student scholars were asked was "when did they know that WCFN was the area they wanted to pursue post-graduation"? Both students describe previous health care related volunteer experiences that helped shape their interest in pediatric or women's health nursing. Student \#1 relayed keeping an open mind during the first year of nursing school but "continued to be drawn" to pediatric nursing. This was validated in her role as a nursing assistant in the neonatal ICU at the end of her first year. Student \#2 relayed her experiences as a volunteer doula for eight years and knew that maternal-child nursing was to be her chosen specialty prior to nursing school.

The second question asked about why they applied to the WCFN student scholar program? Both students reported that they "jumped" at the chance to interview for this program as a way to receive advice, guidance, and information on opportunities about this specialty. More specifically, they sought guidance about their individual career plan and how to reach their professional goals. One student thought it would be a good way to learn more about appropriate conferences, nursing research, and academia.

The third question asked about "whether they would encourage other students to apply to the program" and both students highly recommended the program to future nursing students. Student \#2 commented that being mentored is a "wonderful opportunity to focus your goals, learn from experts, and plan for your future."

The fourth question asked the student scholar about whether "the program was of benefit and if so to describe what the benefits were". Student \#1 benefitted from opportunities made available to her from her mentor that she would not have found otherwise such as tutoring in the Simulation Lab. Similarly, student \#2 appreciated the help in finding professional development experiences. She commented that "the connections provided were enriching (research, a free women's health conference, etc.) and were opportunities I would have been unlikely to have found without my mentor's connections." This student was also able to discuss a particularly challenging patient assignment with her mentor and later applied what she learned on the clinical unit. Both students reported that setting specific goals in the beginning of the program with measurable, attainable outcomes were helpful. Student \#2 reported that taking the time to reflect on what mattered most and set professional goals helped her to learn more about herself. She commented "I tend to think that every area related to women and children is fascinating, so it was imperative that I face this challenge (narrowing the focus) sooner rather than later." Students also agreed that the program made them feel like there was "someone on their team". Student \#1 elaborated, "Attending a large nursing program can make you feel like a small fish in a big pond, and the mentorship program really made me feel like someone actually cared about me as an individual and what would happen to me in my career. That support made me strive to do my best and get involved in more things to advance my career."

Question five focused on "what parts of the program worked well and what could be improved". From the interview process and throughout the program, both students appreciated having set questions and an agenda to plan and guide meetings with her mentor, yet gained from casual conversation as well. Both students agree that meeting once a month is a good balance and having the flexibility to meet more or less often was necessary to meet the mentees' needs yet not feel burdensome. Another component that worked well was the lunches with both faculty and mentees. Student \#2 thought this time was important to explore other areas of women's and children's nursing, discuss relevant research work, get to know the mentors better and "develop a trusting relationship".

To improve the program for future students, both mentees firmly agreed that the opportunity to participate should be available earlier in the curriculum. This would be beneficial "in order to take advantage of more opportunities earlier on and it would give more time to build a strong professional mentorship relationship." Student \#1 felt that her options to attend conferences were limited given the short time frame of the relationship. Student \#2 thought that the program could culminate in a scholarly product such as a poster or paper that would showcase the work of the mentee and contribute to the 
specialty of WCFN. Rather than be an additional scholarly activity, the project could meet the requirements for a class assignment.

The last question asked about "what they would tell future scholars about the program". Both students felt that the mentor program was a great way to develop and advance their professional career. For student \#1, participation in the program helped her to publish her capstone project and submit a poster. For student \#2, it was a good opportunity to "try on" some of the various nursing roles available such as researcher or teacher. She would tell future nursing students to apply for the program because as a scholar, "you can develop a mentoring relationship with a distinguished faculty member. It is a wonderful step toward personal and career growth.' With regards to the transition experience from student to RN, one student commented that participation in the mentoring program helped her to "critically consider opportunities laid before me for expanding my role. I have a better sense of the need to strategically break down these opportunities and contemplate where my goals and strengths lie." Her exposure to the role of researcher with her mentor gave her the confidence to apply for a research opportunity at her first job. She said "I feel that I can understand and be an asset in research in part because I had a little introduction to it with WCFN nurse scholar program and my capstone project."

Faculty mentors were asked about their perspective regarding mentoring and why they wanted to be involved in the program. When asked about why mentor? One faculty mentor stated that they "Wished they had had a mentor to help identify a professional niche earlier", while the other faculty mentor state that "I had a mentor who helped me navigate and get involved in the profession early on in my career and this is a way to give back." When the faculty mentors were asked about how they approached the student mentor relationship, both stated that they took a fairly structured approach to meetings with having a meeting purpose, helping the student scholar establishing goals early in the relationship, and reviewing progress toward meeting on goals. Both faculty mentors set ground rules for maintaining professionalism, accountability, and confidentiality throughout the program. Both faculty mentors were grateful for the willingness of their clinical contacts to provide other types of clinical experiences.

Faculty mentors described numerous benefits to serving in the role of faculty mentor. One benefit was that it seemed like such a simple thing to do, yet the rewards were great! One student scholar offered to meet with an advisee of the mentor who wanted to learn more about becoming a doula. This scholar also assisted with data entry for the faculty men- tor's research. The other faculty mentor talked about the joy she felt in witnessing the excitement and enthusiasm of the student scholar when her poster was accepted and then because of a speaker cancellation coupled with her well written abstract, her poster submission was elevated to that of a podium presentation. This was an experience that the student scholar may not have had if not enrolled in the program.

\section{Discussion}

The results imply that there are several benefits to continuing the WCFN Student Scholar program. These benefits are a result of student scholars working with an expert in WCFN and participating in opportunities for clinical, professional, and personal growth. For the students, clinical growth opportunities consisted of exposure to other clinical experts, and/or other clinical experiences. Professional growth opportunities included gaining assistance in navigating academic/professional resources, expansion of college, university, and organizational networks, role modeling professional etiquette, and opportunities to begin a foundation for scholarship, (eg. poster, presentation, manuscript). Personal growth opportunities entailed working with other clinical experts, learning how to acquire their first professional nursing position, and investigating educational opportunities post-graduation. In addition, there is intangible value that arises from the student-faculty connection itself, such as knowing, trust, respect, and mutuality. These qualities, when present, help students gain insight into their potential and begin to grow personally and professionally. ${ }^{[9]}$ For the faulty mentors there is a satisfaction in knowing that they contributed to the field through improving the quality of the workforce and guiding those with a clinical interest in WCFN to pursue their professional goals.

Both faculty mentors used a blended style of mentoring, with roles including that of sponsor, coach, and advisor as described by McBurney. ${ }^{[11]}$ The roles changed depending on the various goals of the student scholar. For example, student \#1 needed a sponsor to obtain tutoring experience in the university's simulation lab and then a coach to assist with developing a presentation for a professional conference. Student \#2 also benefitted from the faculty mentor's sponsorship to participate in research and attend a professional conference. Both faculty also acted as advisors, sharing their wisdom gained from years of experience to promote professional growth.

Both student scholars preferred having a structure to the meetings with an agenda and area of focus but they also appreciated and found value in the casual conversation that naturally occurred at meetings and at the two lunch sessions with the other faculty-scholar pair. As found in the lunches 
shared with students described by Lewinski and collegues, ${ }^{[3]}$ the scholars in our pilot found that this time for mutual discovery helped build trust. In addition, both WCFN scholars initially participated in face-to-face bi-weekly meetings with their faculty mentor which appropriately spaced out to monthly meetings over time as students became very busy in their final semester and they worked toward their goals. In between these meetings, the pair used email to communicate as needed. As described by Tsai and Helsel, the mentors agreed early on the let the students "drive the ship" in the relationship. ${ }^{[13]}$ This meant that despite busy schedules and fewer face-to-face meetings, the mentors counted on the students to be proactive to remain engaged.

The mentees were drawn to WCFN specialty prior to or during nursing school and sought opportunities to validate this belief. They applied to the scholar pilot program to find out even more about this specialty and receive guidance from an expert. With regards to the program itself, the mentees found it to be beneficial and would recommend it to others. The most significant reason they would recommend it was because of the direction they received towards opportunities that they would not have otherwise found on their own. This is similar to the program described by Lewinski and colleagues ${ }^{[3]}$ where students learned of their shared professional interests with faculty, leading to opportunities they might never have had, including research.

\subsection{Program recommendations}

Recommendations for the program include offering the program earlier in the student program of study to allow more time for the student scholar/faculty mentor pair to work together. Consider steering the mentoring towards those students who need it most; those most vulnerable and at higher risk of attrition; those who perceive they have limited access to resources or are less likely to navigate successfully. While not a primary goal for this mentorship program, our results further support the role mentoring can play as an evidencebased strategy to increase student retention and enthusiasm for their nursing program. ${ }^{[14]}$ It is important to continue to include the opportunity to share a meal once mentor/mentee matches have been made as a way to initiate the mentoring relationship and to provide a relaxing environment for discussion. Vianden ${ }^{[12]}$ found that college students can be uncomfortable talking with faculty and may not know what to say but meeting over a lunch and having goals for that meeting was helpful to "break the ice" and helped set the tone for the experience. A strength of this program was the intentional mentor-mentee pairing based on students' interests gleaned during the interview process. As described by Nelson, et al. the relationship is more of a partnership with the role of the mentor as facilitator for the student. This role is enhanced with thoughtful matching of mentorship pairs. ${ }^{[15]}$ Future program end evaluations could be given several months after graduation to examine the relationship between participation in the mentoring program and transition to the $\mathrm{RN}$ role.

\section{Conclusion}

Implementing a WCFN student scholar pilot program provided students with the opportunity to be mentored by a clinical expert in WCFN. While the WCFN student scholar program was developed with the students in mind, there were benefits for the faculty mentor as well. The individualized attention the students received from an experienced faculty member confirmed their belief that a clinical position in the specialty of WCFN was the correct career path post-graduation. Recognizing and supporting students with an interest in WCFN can foster the pursuit of WCFN clinical employment for these students upon graduation. Nursing programs should consider strategies to incorporate informal interaction as a way to strengthen student-faculty relationships. These efforts will have a positive impact on the nursing workforce and could help to reduce the nurse faculty shortage.

\section{CONFlicts OF InTEREST Disclosure}

The authors declare that there is no conflict of interest.

\section{REFERENCES}

[1] Ingraham K, Davidson S, Yonge O. Student-faculty relationships and its impact on academic outcomes. Nurse Educ Today. 2018; 71: 1721. PMid:30212706 https://doi .org/10.1016/j . nedt. 2018. 08.021

[2] Clark C. The power and potential of positive mentoring. Nurse Educ. 2015; 40(3): 109 121. PMid:25763782 https ://doi.org/10.109 7/NNE. 0000000000000158

[3] Lewinski A, Wainwright K, Gordon H, et al. Student-faculty lunch program to increase mentoring and facilitate cross-program relationships in school of nursing. Nurse Educ. 2016; 41(93): 143-146. PMid:26465347 https://doi.org/10.1097/NNE.0000000000

Published by Sciedu Press
000220

[4] Chickering A, Gamson Z. Appendix A: Seven principles for good practice in undergraduate education. New Directions for Teaching and Learning. 1991; 47: 63-69. https://doi.org/10.1002/t1 .37219914708

[5] Eby L, Allens T, Evans S, Ng T, et al. Does mentoring matter? A multidisciplinary meta-analysis comparing mentored and non-mentored individuals. J Vocat Behav. 2008; 72(2): 254-267. PMid:19343074 https://doi.org/10.1016/j.jvb.2007.04.005

[6] Al-Hussami M, Saleh M, Hayajneh F, et al. The effects of undergraduate nursing student-faculty interaction outside the classroom on college grade point average. Nursing Educa Pract. 2011; 11: 320-326. 
PMid:21367660 https://doi.org/10.1016/j.nepr. 2011.02 .004

[7] Hernandez P, Bloodhart B, Barnes R, et al. Promoting professional identity, motivation, and persistence: Benefits of an informal mentoring program for female undergraduate students. Plos One. 2017. PMid:29091969 https ://doi.org/10.1371/journal.pone.0 187531

[8] Dorsey L, Baker C. Mentoring undergraduate nursing students: Assessing the state of the science. Nurse Educ. 2004; 29(6): 260-265. PMid:15586124 https ://doi.org/10.1097/00006223-20041 1000-00013

[9] Gillespie M. Student-teacher connection: A place of possibility. J Adv Nurs. 2005; 52(2): 211-219. PMid:16164482 https://doi. org/10.1111/j.1365-2648.2005.03581.x

[10] Price S, Hall L, Murphy G, et al. Evolving career choice narratives of new graduate nurses. Nurse Education in Practice. 2018; 28: 86-91. PMid:29055234 https://doi.org/10.1016/j.nepr.2017.10 .007
[11] McBurney E. Strategic mentoring: Growth for mentor and mentee. Clin Dermatol. 2015; 33: 257-260. PMid:25704946 https ://doi. org/10.1016/j.clindermatol.2014.12.019

[12] Vianden J. Exploring college men's perceptions about interacting with faculty beyond the classroom. College Student Affairs Journal. 2009; 27(2): 224-241.

[13] Tsai P, Helsel B. How to build effective mentor-mentee relationships: Role of the mentee. Journal of Thoracic and Cardiovascular Surgery. 2016; 151(3): 642-644. PMid:26548999 https: //doi.org/10.1016/j.jtcvs.2015.10.017

[14] Bumby JC. Evidence-based interventions for retention of nursing students: A review of the literature. Nurse Educ. 2020; 45(6): 312-315. PMid:31972843 https://doi.org/10.1097/NNE. 0000000000 000797

[15] Nelson N, Lim F, Navarra A, et al. Faculty and student perspectives on mentorship in a nursing honors program. Nursing education Perspectives. 2018; 39(1): 29-31. PMid:29053526 https: //doi.org/10.1097/01.NEP.0000000000000197 